\title{
Development of macular vessels in monkey and cat
}

\author{
PAUL HENKIND, ROY W. BELLHORN, MARY ELLEN MURPHY, AND \\ NOEL ROA \\ From the Department of Ophthalmology, Albert Einstein College of Medicine \\ and Montefiore Hospital Medical Center, New York
}

It has long been recognized that a distinct vascular pattern exists in the macular region in man and animals. In man and higher primates, a 'capillaryfree' zone is present at the fovea, but the exact extent of this zone is now in question(Yeung, Crock, Cairns, Heinze, Troski, and Billson, 1973; Bird and Weale, 1974). Other animals possess a relatively sparse capillary bed in the region of the area centralis.

We have been interested to know how the macular vascular pattern arises. Virtually nothing has been written about the development of macular vessels in any animal species including man. We have chosen to study the subject in both the rhesus monkey, a primate whose adult macular vascularization approximates to that of man (de Oliveira and Ripps, 1968) and the cat, an animal with a distinct area centralis (Stone, 1965 ; Steinberg, Reid, and Lacy, 1974), but no fovea. This report concerns our preliminary observations.

\section{Material and methods}

Our studies were conducted on kittens, ranging in age from I day to $13 \mathrm{wk}$, and on Caesarian-delivered fetal rhesus monkeys and neonates. Preparations of the retinal vascular system injected with Indian ink were prepared as previously described (Henkind, 1966), or retinal digests were prepared according to a modified Kuwabara and Cogan (I 960) technique. Preparations were examined by light microscopy and photographed with a Zeiss Ultraphot microscope.

\section{FINDINGS}

Most of the data are derived from the preparations injected with Indian ink primarily because of our technical difficulty in preparing adequate digests from immature retinae. Our findings in the kitten are listed in Table I and in the monkey in Table II.

Supported by N.I.H. Grant EYoo6 13 and an unrestricted Grant from Research to Prevent Blindness

Requests for reprints: Professor P. Henkind, Department of Ophthalmology, Albert Einstein College of Medicine and Montefiore Hospital Medical Center, 11 I East 2 roth Street, Bronx, New York 10467, USA

\section{Kitten}

Information provided by analysis of retinal vessel preparations injected with Indian ink is not always conclusive because the injection may be only partial, and does not permit total examination of the developing vascular complex (Henkind and de Oliveira, 1967). Injected preparations, however, do provide some clues as to the presence of open vascular channels. The newborn kitten has vascular complexes which fill with ink, extending 5 to $6 \mathrm{~mm}$ along its major vessel arcades (Michaelson, 1954). At this time, and up to 2 wk thereafter, the area centralis, the geographical region several disc diameters from the disc, and almost exactly in between the superior and inferior vascular arcades, is still devoid of injected capillary channels (Fig. I). This situation more or less persists until some time before the twenty-first day, by which time ink-filled vessels are observed traversing the area centralis. Of some interest is the observation that the macular capillaries did not appear to develop from the immature type meshwork seen in other portions of the retina (Fig. I) (Michaelson, 1954). Perhaps, the immature stage was missed in our sampling, but a similar situation was noted in the development of the radial peripapillary capillaries in the cat (Henkind, Bellhorn, and Poll, 1973). By the seventh week, partial thinning of the capillary zone in the area centralis can be seen (Fig. 2). Michaelson (1954) described an almost completely avascular macular zone measuring some $300 \mu \mathrm{m}$ in the cat; we have never seen an area of such magnitude devoid of vessels in well injected adult specimens. Conceivably, the avascular zone continues to enlarge with age as the initial vessels of the area centralis atrophy or occlude. On the other hand, we have noted on a number of occasions that when injection is less than optimal the area centralis region tends to suffer most from lack of ink perfusion. The meaning of this observation is open to conjecture, but may suggest some physiologically significant differences between the macular and nonmacular retinal circulation.

\section{Rhesus monkey}

A fully vascularized central macular region with two distinct levels of capillaries is present in fetal life (Fig. 3). It is important to examine well injected specimens because inadequately injected preparations can mislead and provide an impression of an avascular central region (Figs $4 a, b$ ). As in the kitten, it seems that the 
Table I Development of area centralis vessels in the cat

\begin{tabular}{|c|c|c|}
\hline $\begin{array}{l}\text { Postnatal } \\
\text { day }\end{array}$ & $\begin{array}{l}\text { Cat } \\
\text { no. }\end{array}$ & Comment on the inked specimen \\
\hline $\mathbf{I}$ & $\begin{array}{l}\text { F } 160 \\
\text { F } 161\end{array}$ & $\begin{array}{l}\text { No vessels in area centralis } \\
\text { No vessels in area centralis }\end{array}$ \\
\hline $\begin{array}{l}3 \\
3\end{array}$ & $\begin{array}{l}\text { F } 151 \\
\text { F } 209\end{array}$ & $\begin{array}{l}\text { No vessels in area centralis } \\
\text { Inked channels just reaching area centralis }\end{array}$ \\
\hline 7 & F 154 & No vessels in area centralis \\
\hline 14 & F 211 & $\begin{array}{l}\text { Avascular area centralis, surrounding central retinal zone does not show immature } \\
\text { pattern }\end{array}$ \\
\hline 14 & F 156 & Apparent vessel-free area centralis \\
\hline 21 & F 157 & Area centralis fully vascularized, and a double layer of capillaries is seen \\
\hline 25 & F 158 & No capillary-free zone \\
\hline $\begin{array}{l}28 \\
28 \\
28\end{array}$ & $\begin{array}{l}\text { F } 159 \\
\text { F } 88 \\
\text { F } 80\end{array}$ & $\begin{array}{l}\text { No capillary-free zone } \\
\text { A few vessels poorly filled in area centralis, but no capillary-free zone } \\
\text { Similar to F } 88\end{array}$ \\
\hline 35 & F 176 & Area centralis has perhaps less dense capillary bed than surrounding macula \\
\hline 60 & $P_{32-1}$ & Well vascularized area centralis \\
\hline 90 & F 197 & Some definite thinning out of area centralis capillary bed, but still two layers \\
\hline 90 & F 205 & Definite thinning out of capillaries in area centralis \\
\hline
\end{tabular}

Table II Development of macular vessels in rhesus monkey

\begin{tabular}{|c|c|c|c|}
\hline Day & Monkey no. & Indian ink & Digest \\
\hline $125 \mathrm{~F}$ & Rh 774f & Fully vascularized macula (some artefactual) & \\
\hline $145 \mathrm{~F}$ & $\begin{array}{r}\text { Rh } 2 f(a) \\
\text { if (b) }\end{array}$ & $\begin{array}{l}\text { Fully vascularized macula with two capillary } \\
\text { layers } \\
\text { Opposite eye, poorer inking; spurious } \\
\text { vessel-free central macula }\end{array}$ & \\
\hline I $50 \mathrm{~F}$ & $\begin{array}{r}\text { Rh 864f (a) } \\
864 f(b)\end{array}$ & $\begin{array}{l}\text { Definite capillary-free zone in central macula } \\
\text { Definite thinning out of capillaries of } \\
\text { central macula }\end{array}$ & \\
\hline 3 day & $\begin{array}{r}\text { Rh } 860(a) \\
860(b)\end{array}$ & & $\begin{array}{l}\text { Acellular macula vessel strands } \\
\text { Poor digest, but similar to above }\end{array}$ \\
\hline 20 day & Rh 840 & Thinned out capillaries of central macula & \\
\hline
\end{tabular}

macular region perfuses with greater difficulty than other retinal areas. Towards late fetal or early neonatal life, there is vascular remodelling with the subsequent development of an avascular foveal area (Fig. $5 a, b$ ). This is well demonstrated on a retinal digest preparation where many of the capillaries in the central zone appear as acellular strands (Fig. 6). Continuation of this remodelling process leads to the formation of the completely avascular foveal area observed in the mature rhesus monkey (Fig. 7). Whether or not the early capillaries seen traversing the region of the fetal retina and destined to become the fovea arise like other retinal capillaries 


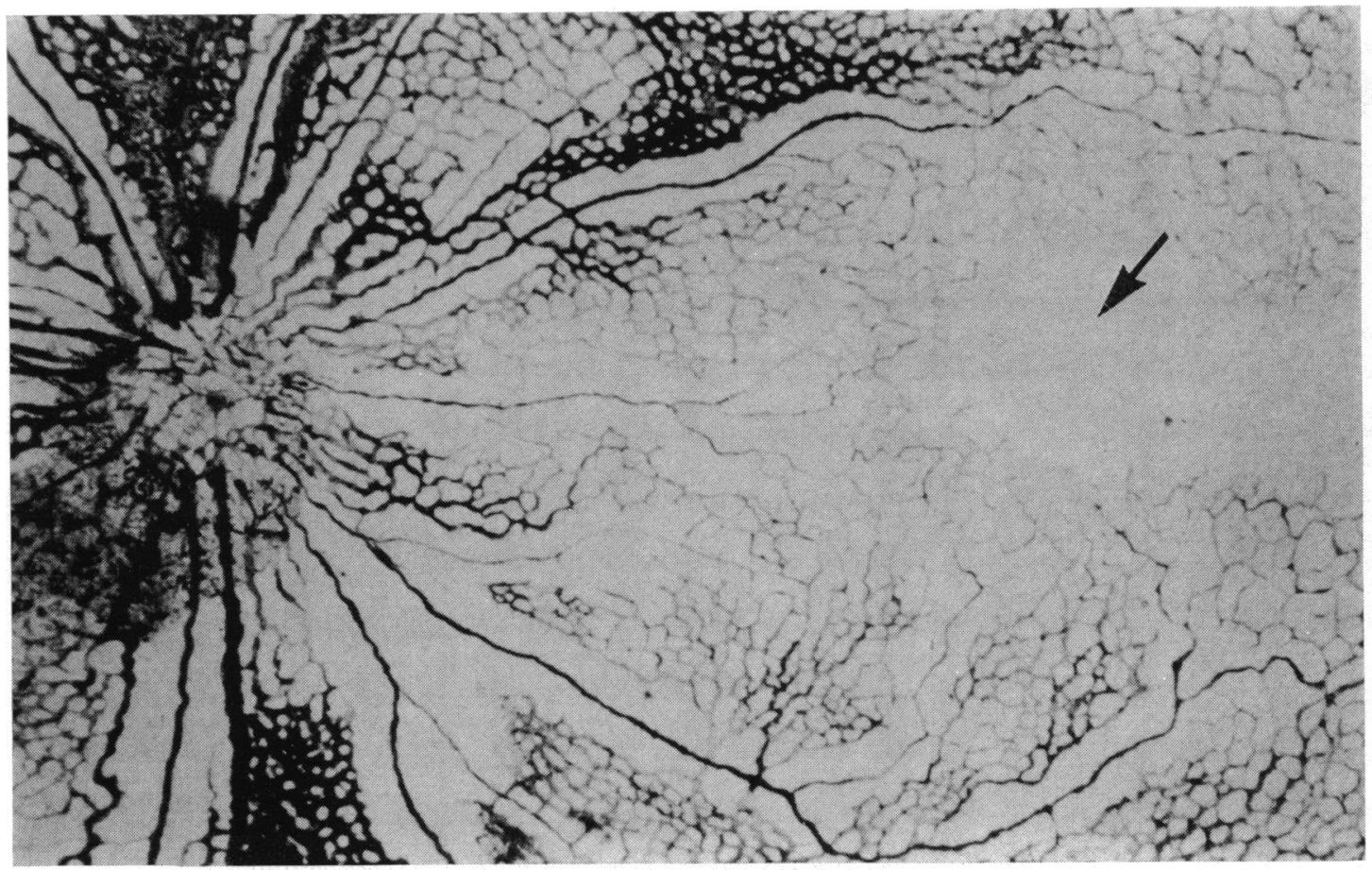

FIG. I Flat preparation of ink-injected retina of a 14-day-old kitten (No. 2 I I). Region of area centralis (arrow) does not yet possess ink-filled vascular channels. Note that some capillaries near optic disc and area centralis have the narrower lumen and wider pattern characteristic of fully developed (mature) capillary beds. Other capillaries are tightly packed and have broad lumens, and this pattern is termed immature. $\times 25$

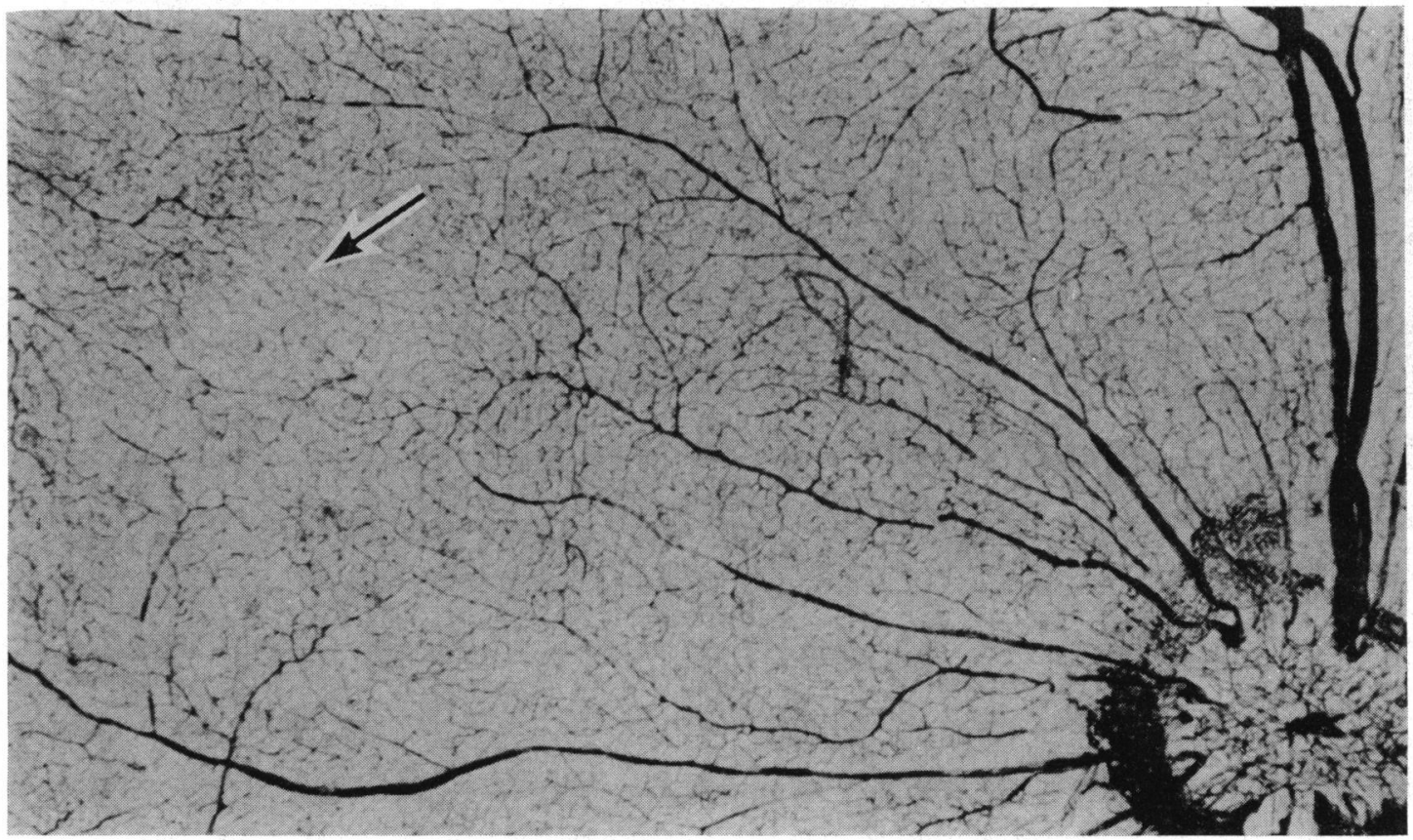

FIG. 2 Flat preparation of ink-injected retina of a 35-day-old kitten (No. 176). A partial thinning of the capillary network in the area centralis (arrow) is apparent. $\times 30$ 


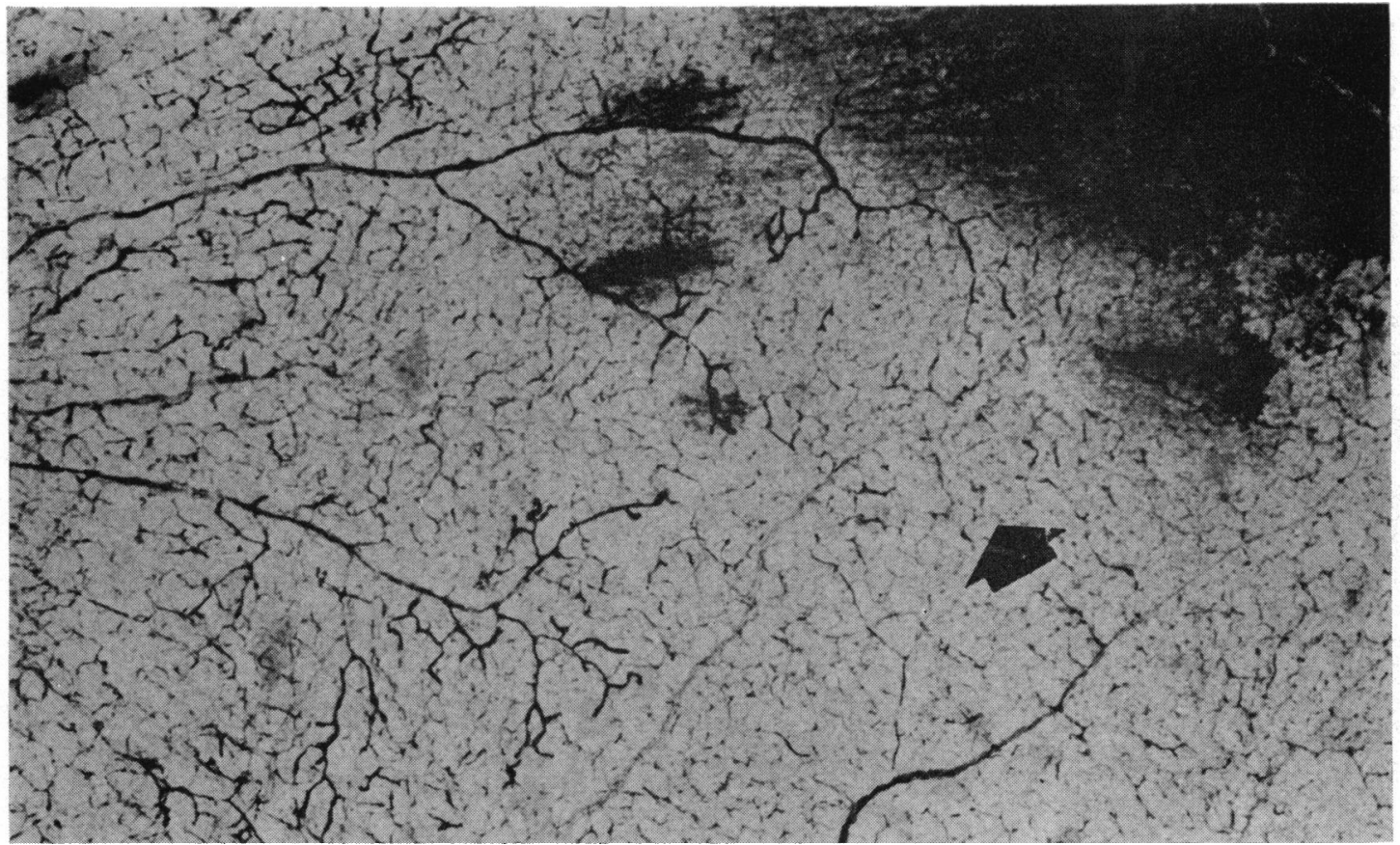

FIG. 3 Flat preparation of ink-injected retina of a 125-day-old monkey fetus (No. 774) demonstrating generalized vascularization of macula and fovea (large arrow). The black smudges are artefactual leaks. $\times 50$

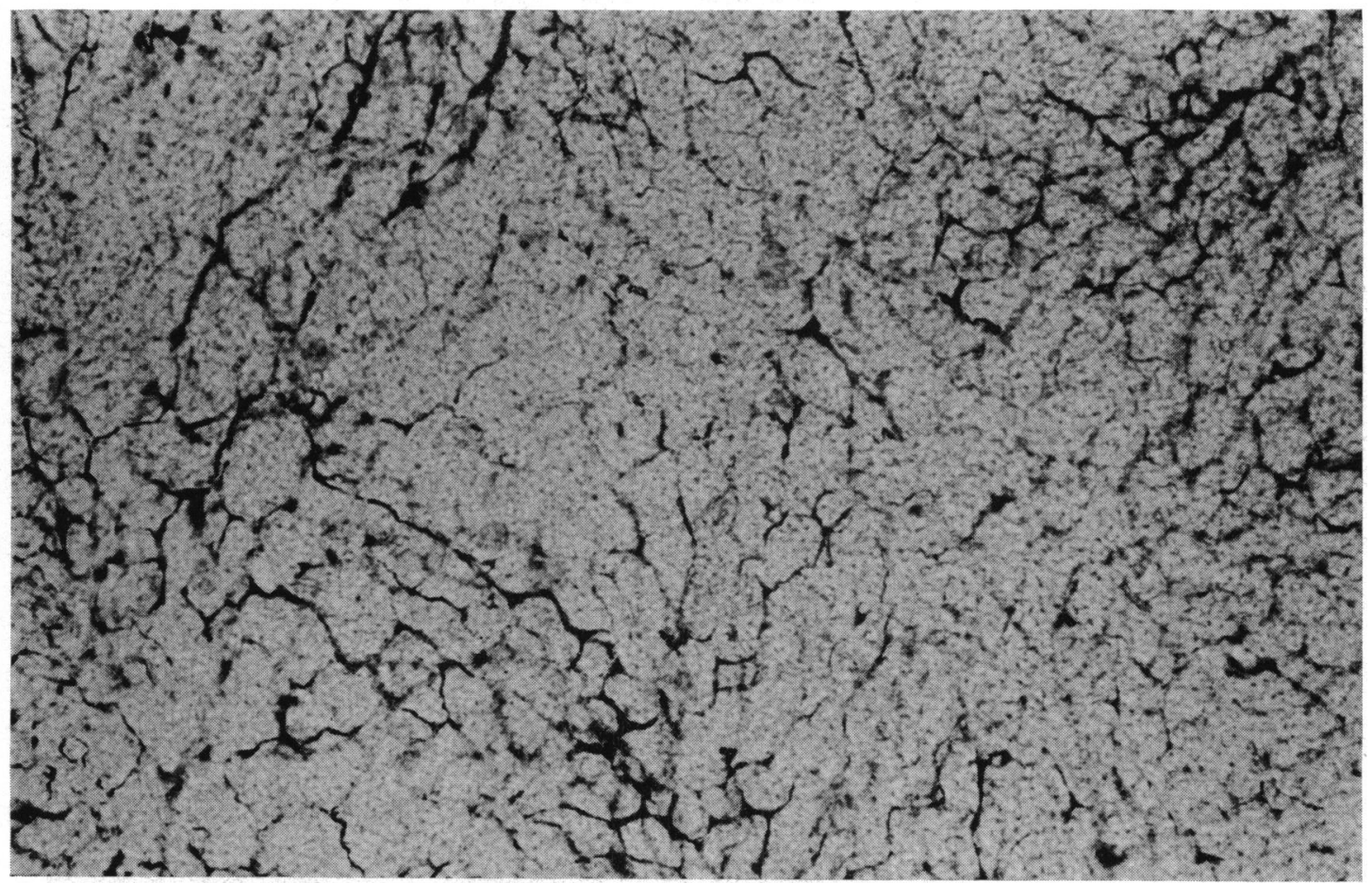

FIG. 4a. Flat preparation of ink-injected retina of a 140 to 145 -day-old monkey fetus (No. Rh 2). Focusing the microscope revealed several layers of capillaries in macular region; there was no capillary-free zone. Faint lines denote deeper capillary bed beneath the plane of focus. $\times 125$ 


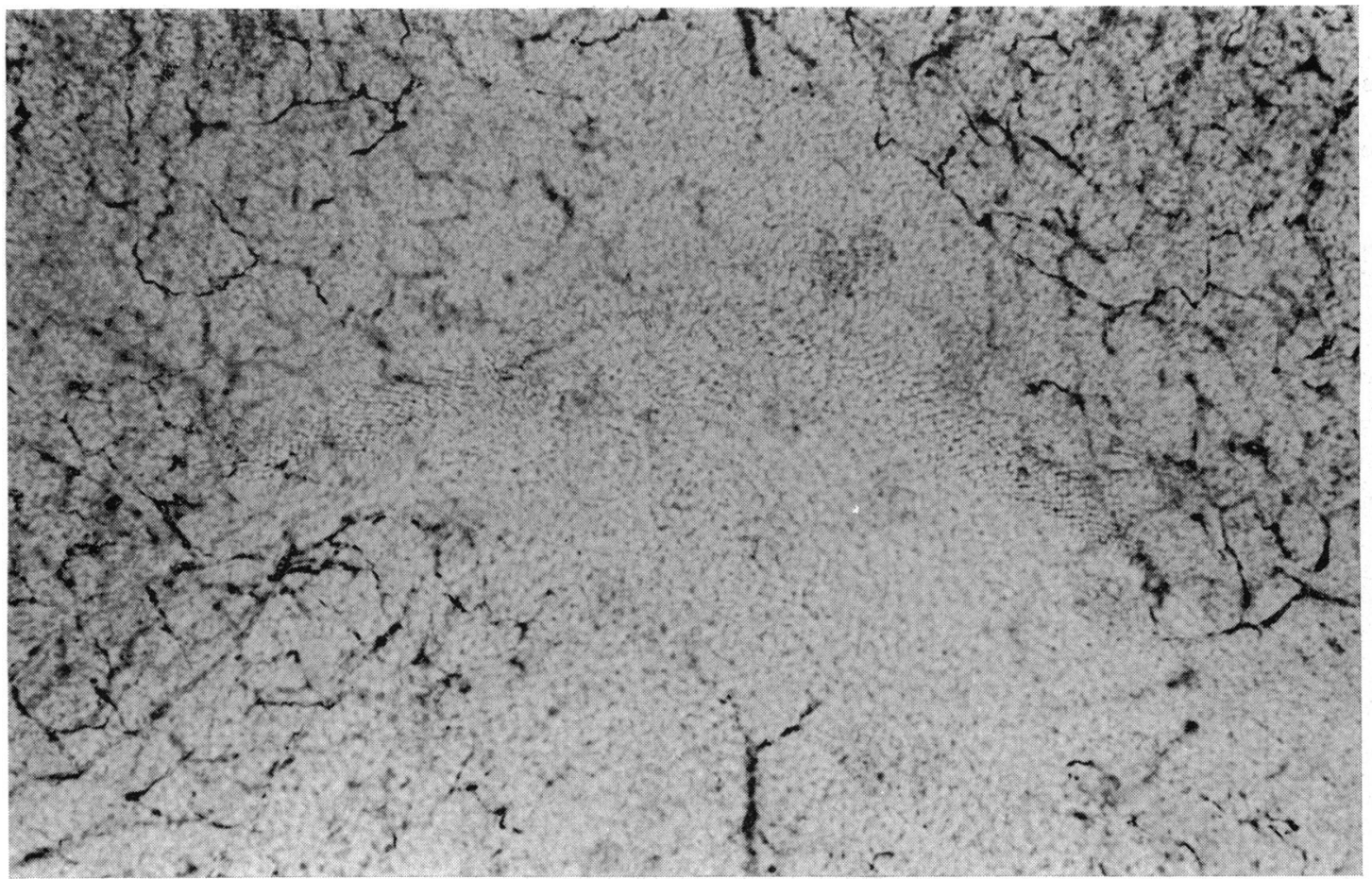

FIG. $4 b$ Opposite eye showing large poorly-perfused area that could readily be mistaken for a vessel-free macular zone. Note faint traces of vessels in that area. $\times 125$

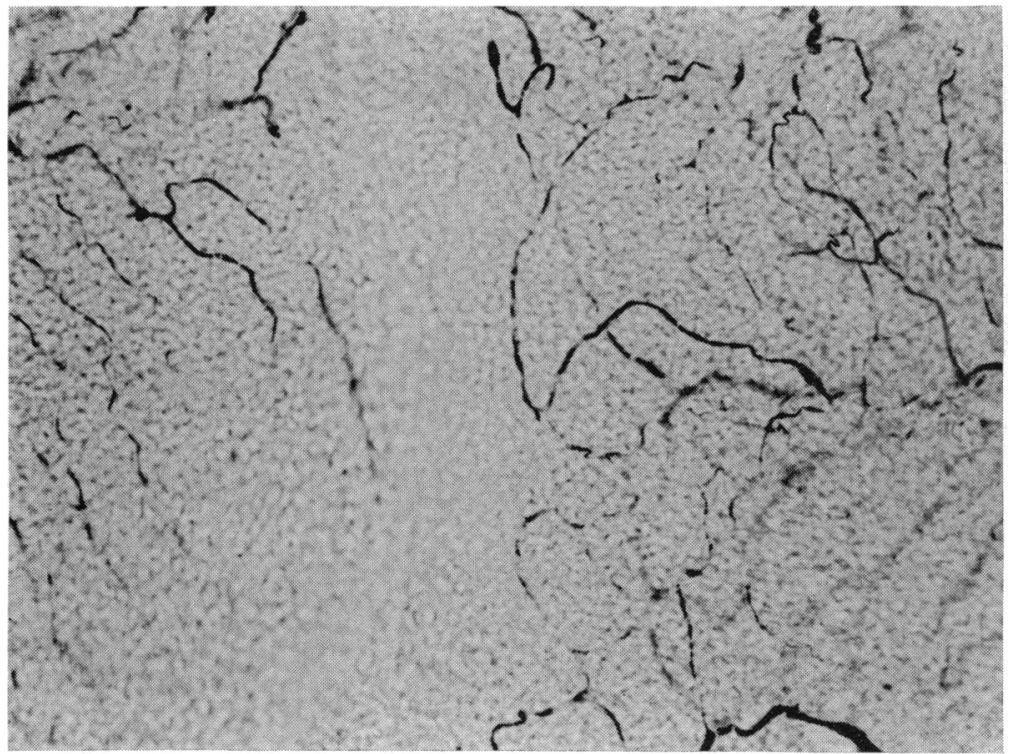

FIG. 5 a Flat preparation of inkinjected retina of a $150-$ day-old monkey fetus (No. 864) showing vessel-free area in fovea. Note presence of capillary arcades indicative of termination of capillary bed rather than artefactual poor filling. Postmortem puckering of macular region makes photography difficult. $\times 125$

(from primitive mesenchymal elements) is not known and would require examination of much earlier material than we currently possess.

\section{Discussion}

Our observations of the developing macular vascu- lature in the rhesus monkey are important in helping to understand the recent observations of Yeung and others (1973) and those of Bird and Weale (1974). Both groups were able to demonstrate by fluorescein angiography, and the latter authors also by a subjective method using scleral 
transillumination, capillaries crossing the human fovea. We, too, have observed fluorescein-filled vessels traversing the foveal zone in some patients. Obviously, these vessels are persisting remnants of the fetal vascular system which have not disappeared.
At least in the rhesus monkey, remodelling of the macular vessels apparently begins before the animal is exposed to visual stimuli. Presumably, a similar situation occurs in man. Whether the vascular alterations occur without concomitant neuroretinal changes, including the development of a

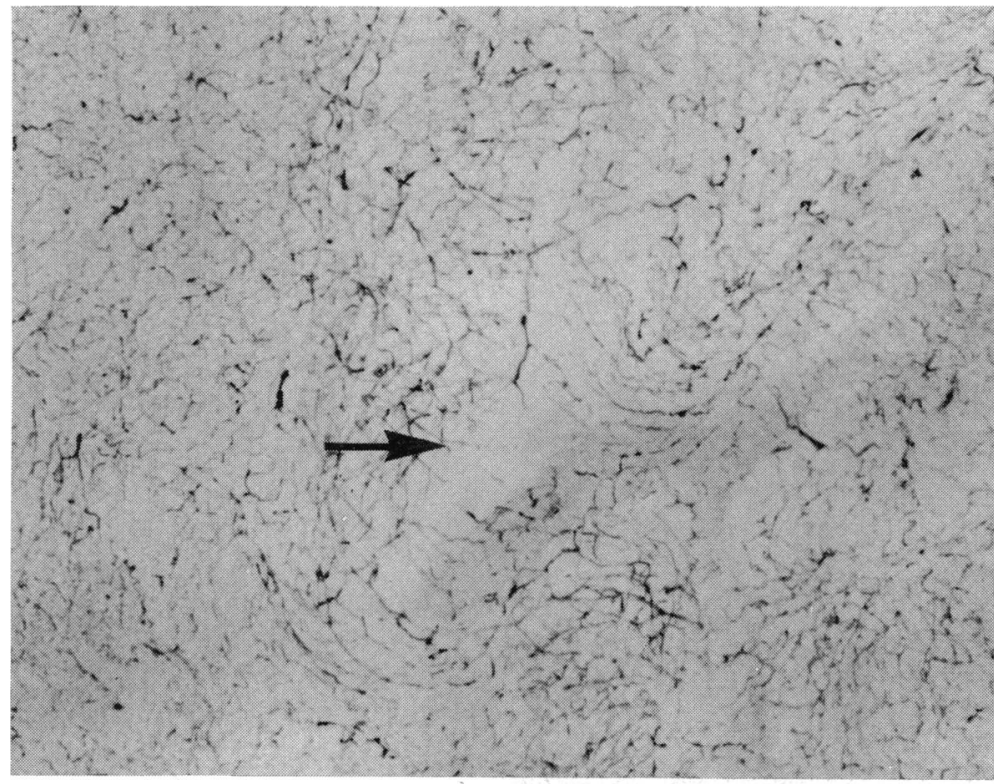

FIG. $5 b$ Flat preparation of inkinjected retina of a 20-day-old monkey (No. 840) showing sparseness of capillaries in macula (arrow). Distortion is again due to macular folds as a result of fixation. $\times 50$

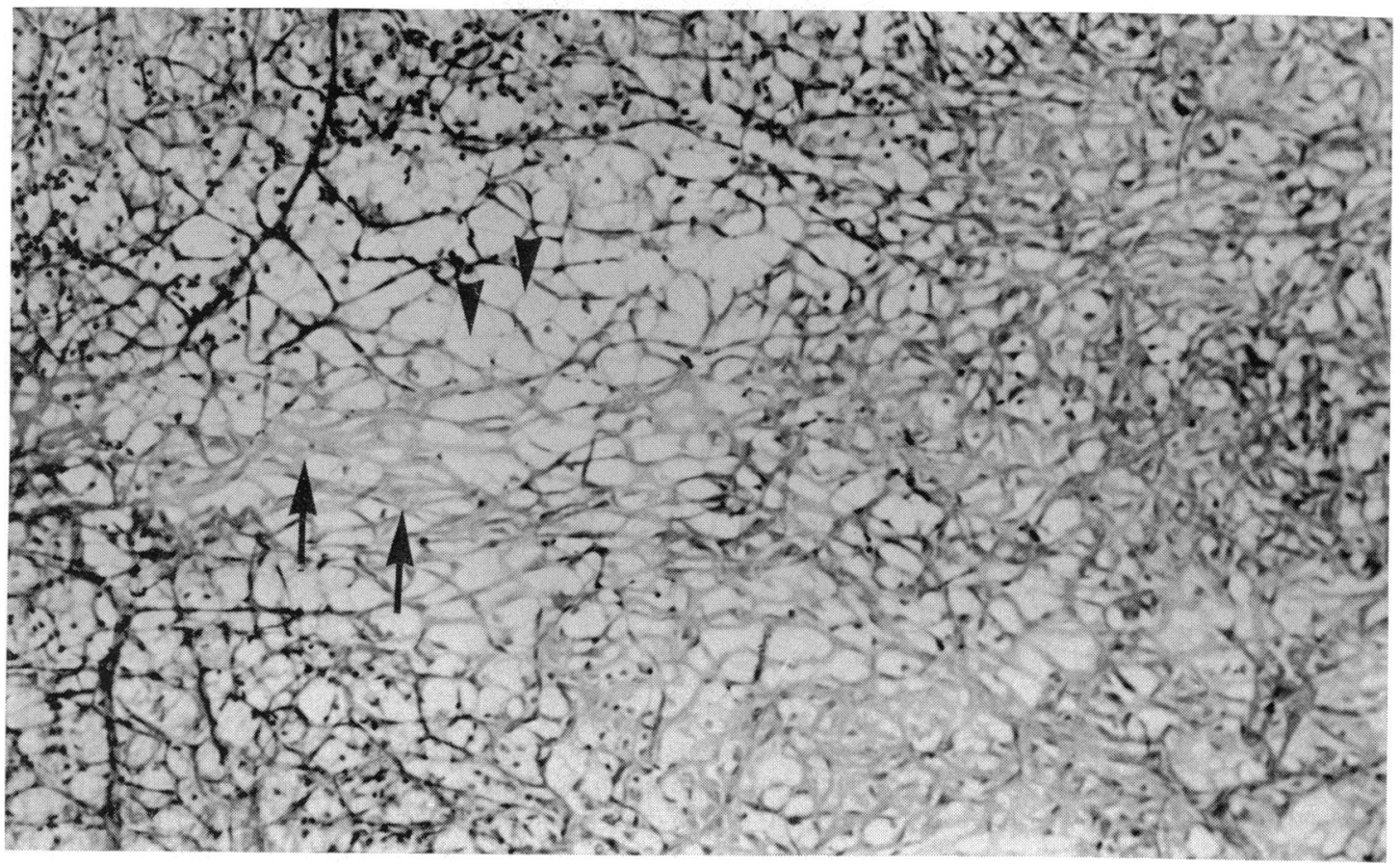

FIG. 6 Retinal digest preparation from 3-day-old monkey (No. 860) showing broad pale staining acellular capillary strands in foveal region (arrows) and very thin acellular strands (arrowheads). Periodic acid-Schiff. $\times 125$ 


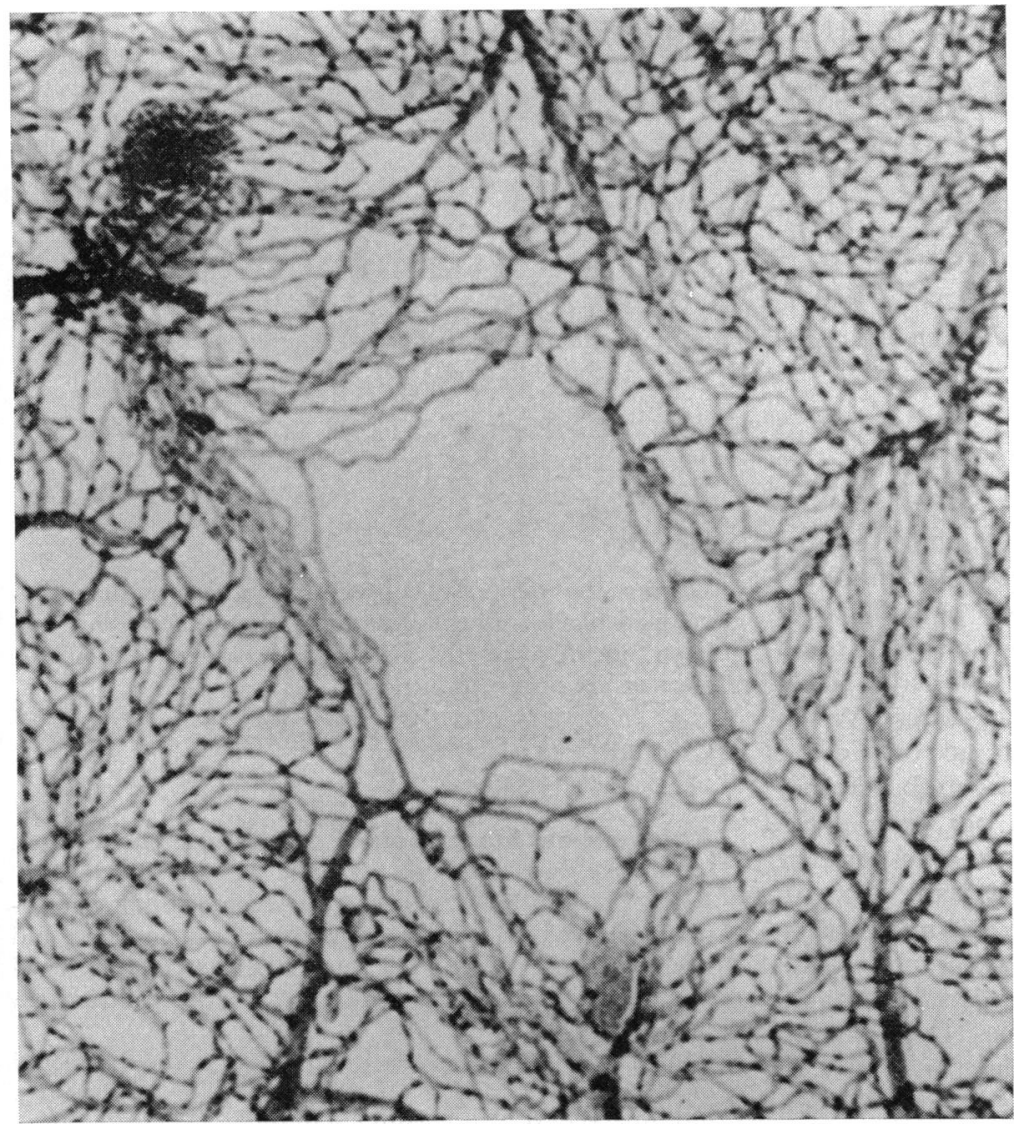

FIG. 7 Retinal digest preparation from adult rhesus monkey (from de Oliveira and Ripps, 1968) showing well-defined vessel-free zone at fovea

foveal pit, is, of course, not yet known, but the question is being examined by our group.

Preliminary studies in which we occluded, by tarsorrhaphy, one eye of newborn kittens have so far failed to reveal any obvious difference in the pattern of macular vascularization as the animal matured. We had wondered whether visual deprivation, which is known to cause amblyopia, would cause an alteration in vascular development; apparently it does not. On the other hand, Yeung and others (1973) noted a number of cases of amblyopia in patients with foveal vessels, but most did not have amblyopia. Bird and Weale's patients all had normal vision. No one, to our knowledge, has examined a large series of congenitally amblyopic patients to ascertain their pattern of macular-foveal vessels.

Further investigations concerning the development of macular vascularization and the relationship of such vascularization to various disease states are warranted.

We are most grateful to J. Moor-Jankowski, MD (Director) and Wendell H. Niemann, DVM (Chief of Reproduction, Perinatal Growth and Development), Laboratory for Experimental Medicine and Surgery in Primates, Sterling Forest, New York, for providing fetal and neonatal monkeys for this investigation.

\section{References}

BIRD, A. C., and WEALE, R. A. (1974) Exp. Eye Res., 19, 409 DE OLIVEIRA, L. F., and RIPPS, H. (1968) Vision Res., 8, 223 HENKIND, P. (1966) Exp. Eye Res., 5, 10

-, BELlHORN, R. W., and POLL, D. (1973) Brit. F. Ophthal., 57, 595

, and DE OLIVEIRA, L. F. (1967) Invest. Ophthal., 6, 520

kuWabara, T., and cogan, D. G. (1960) Arch. Ophthal., 64, 904

michaelson, I. C. (1954) 'Retinal Circulation in Man and Animals'. Thomas, Springfield, Ill.

STEINBERG, R. H., REID, M., and LACY, P. L. (1974) F. comp. Neur., 148, 229

STONE, J. (1965) Ibid., 124, 337

yeUNG, J., CROCK, G., CAIRNS, J., HeINZe, J., Troski, s., and BIllson, f. (1973) Austr. F. Ophthal., r, 7 